\title{
NOTE
}

\section{Restoration of Fertility with Gonadotropin and Bromocriptine in a Hypogonadal Man after Removal of Macroprolactinoma}

\author{
Reiko DEMURA, Emi OdAGIRI, Kazuko, JibIKI, Hiroshi DEMURA, \\ Kazuo SHIZUME, Osami KUBO* and KoIchi KITAMURA* \\ Dept. of Internal Medicine and Neurosurgery*, Tokyo Women's Medical \\ College, 10-Kawadacho, Ichigaya, Shinjuku-ku, Tokyo 162
}

\begin{abstract}
A case of male hypogonadism after removal of macroprolactinoma was successfully treated with gonadotropin. A 35-year-old man treated surgically for pituitary adenoma had elevated plasma prolactin and impaired pituitary function after the operation. $\mathrm{He}$ was on replacement of hydrocortisone, levothyroxine and testosterone depot along with bromocriptine. Normal plasma testosterone levels were achieved with HCG, 3,000 IU three times a week. The addition of $75 \mathrm{IU}$ of FSH daily restored spermatogenesis and the sperm count reached the fertile range at the 11th month. Doses of HCG and FSH were cut in half at the 10th month without affecting the plasma testosterone levels. His wife was impregnated at the 12th month and gave birth to a normal baby girl.
\end{abstract}

Though hyperprolactinemia, a common cause of infertility in both sexes, is readily treatable, associated hypogonadism due to impaired pituitary function is a serious problem. Combined HCG and HMG therapy along with bromocriptine successfully restored spermatogenesis in a man with longstanding postoperative hypopituitarism due to macroprolactinoma.

\section{Case Report}

M. K., a 35-year-old man visited the hospital 9 years ago for the evaluation of postoperative pituitary function as he underwent transfrontal hypophysectomy for pituitary adenoma which had extended suprasel-

Received March 5, 1984
Table 1. Pituitary function tests.

a. Responses of LH, FSH, TSH and PRL to $100 \mu \mathrm{g}$ of LH-RH and 500 $\mu \mathrm{g}$ of TRH.

b. Responses of $\mathrm{GH}$ and cortisol to $0.1 \mathrm{U} / \mathrm{kg}$ of regular insulin.

a. LH-RH, TRH test

\begin{tabular}{lcccc}
\hline \hline Tormone & 0 & 30 & 60 & 90 \\
\hline LH (mIU $/ \mathrm{ml})$ & 1.0 & 4.2 & 5.2 & 4.2 \\
FSH $(\mathrm{mIU} / \mathrm{ml})$ & 0.2 & 0.1 & 0.2 & 0.3 \\
TSH $(\mu \mathrm{U} / \mathrm{ml})$ & n.d. & 0.5 & 0.5 & 0.5 \\
PRL $(\mathrm{ng} / \mathrm{ml})$ & 250 & 268 & 280 & 272 \\
\hline
\end{tabular}

b. ITT

\begin{tabular}{lcccc}
\hline \hline Hormone & 0 & 30 & 60 & 90 \\
\hline GH $(\mathrm{ng} / \mathrm{ml})$ & n.d. & n.d. & n.d. & n.d. \\
Cortisol* $(\mu \mathrm{g} / \mathrm{dl})$ & 17 & & 21 & 15 \\
\hline * on replacement & & & &
\end{tabular}


lary and caused visual disturbances. He therapy was started.

was $169 \mathrm{~cm}$ tall and weighed $58 \mathrm{~kg}$ and had a feminine body structure. Axillary and public hair were sparce and the testes were small and soft. No gynecomastia or galactorrhea were noted. Pituitary function tests revealed impaired reserve of all hormones with markedly elevated plasma prolactin levels (Table 1). Replacement therapy of hydrocortisone at $20 \mathrm{mg} /$ day, levothyroxine $100 \mu \mathrm{g} /$ day and testosterone depot at 125 $\mathrm{mg} / 2$ weeks were started with $7.5 \mathrm{mg} /$ day of bromocriptine. Urological examination revealed complete azoospermia with marked1y atrophied testes on biopsy (Fig. 1). Eight years later, he married and eagerly wanted to become a father and then gonadotropin

\section{Materials and Methods}

Pituitary function tests were performed with LH-RH and TRH tests and insulin tolerance test by injecting $100 \mu \mathrm{g}$ of LH-RH and $500 \mu \mathrm{g}$ of TRH simultaneously, and $0.1 \mathrm{IU} / \mathrm{kg}$ of regular insulin, respectively. Plasma LH and FSH were measured by radioimmunoassay (RIA) using kits made by Eiken, ICL, Japan. Plasma testosterone was measured by RIA using our own artibody and plasma prolactin with a RIA kit kindly supplied by NIAMDD, Maryland, USA. Normal ranges of $\mathrm{LH}, \mathrm{FSH}$, testosterone and prolactin for a male were $3-16 \mathrm{mIU} / \mathrm{ml}, 2-9 \mathrm{mIU} / \mathrm{ml}, 275$ $1100 \mathrm{ng} / \mathrm{dl}$ and $2-20 \mathrm{ng} / \mathrm{ml}$, respectively.

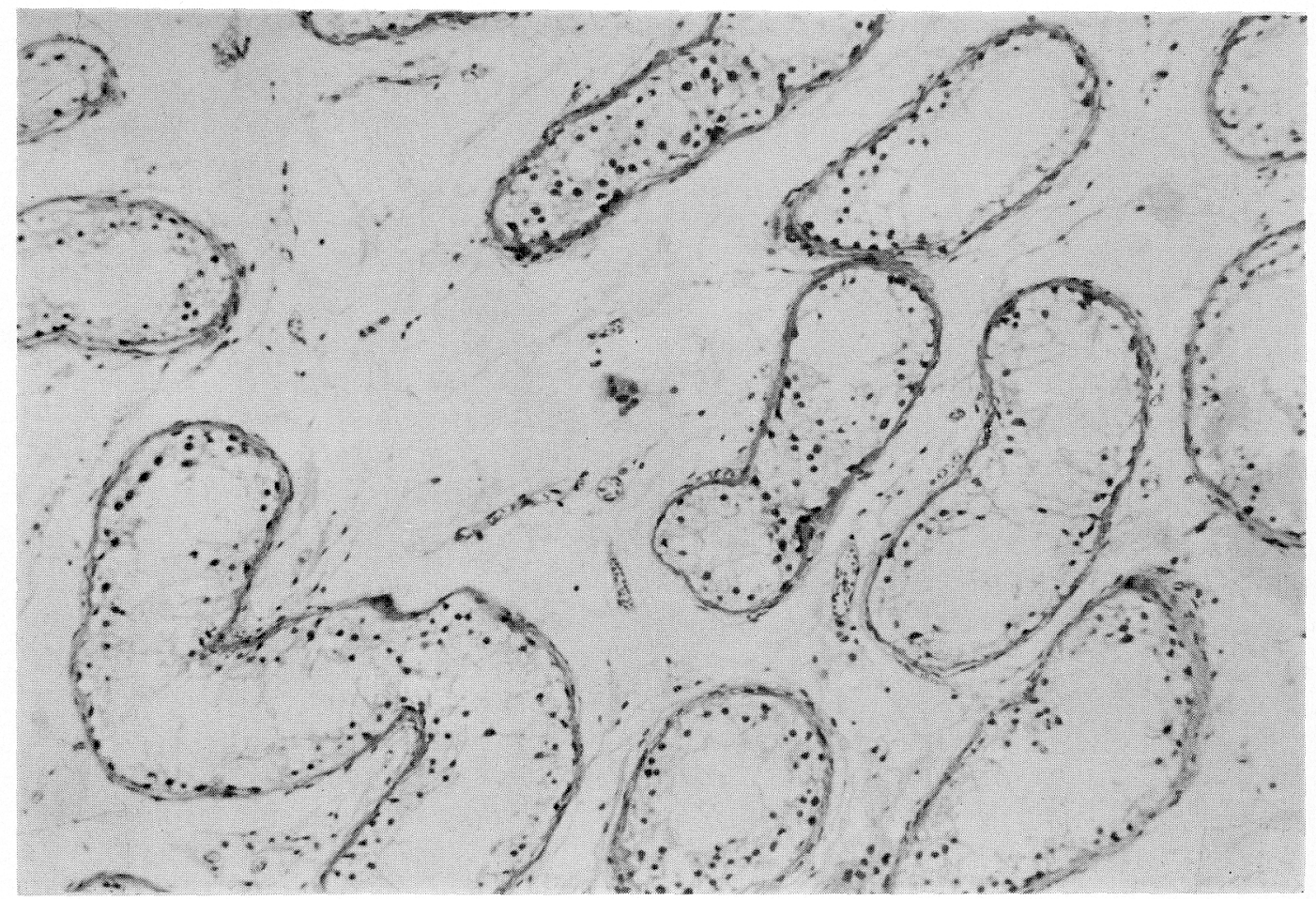

Fig. 1. Histology of testicular biopsy $(\times 400)$. Seminiferous tubules were generally atrophic with moderate thickening of basement membrane and edematous dispersion of stroma. The tubules were mainly composed of Sertoli cells and the germinal cell population was evidently low indicating immaturity. In the stroma, small groups of fibroblast-like cells were detected but no mature Leydig cells. 


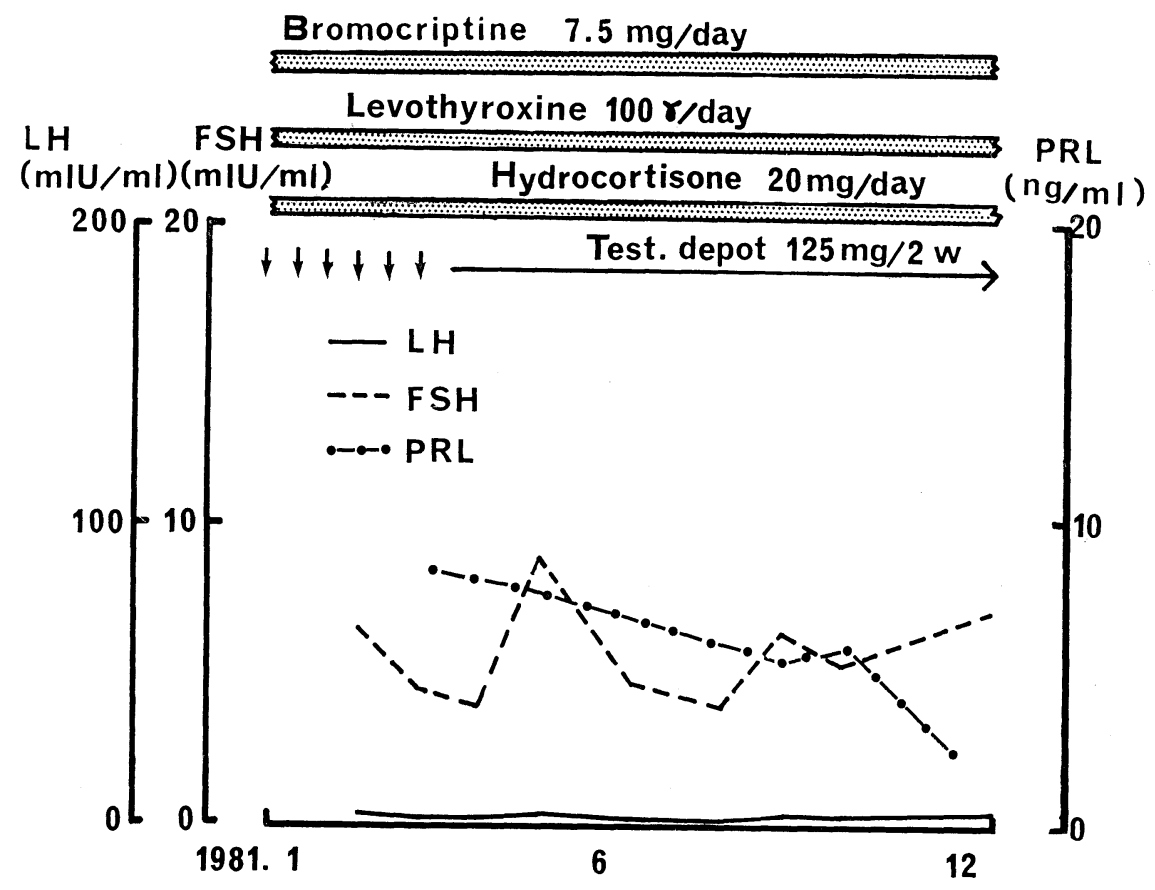

Test.

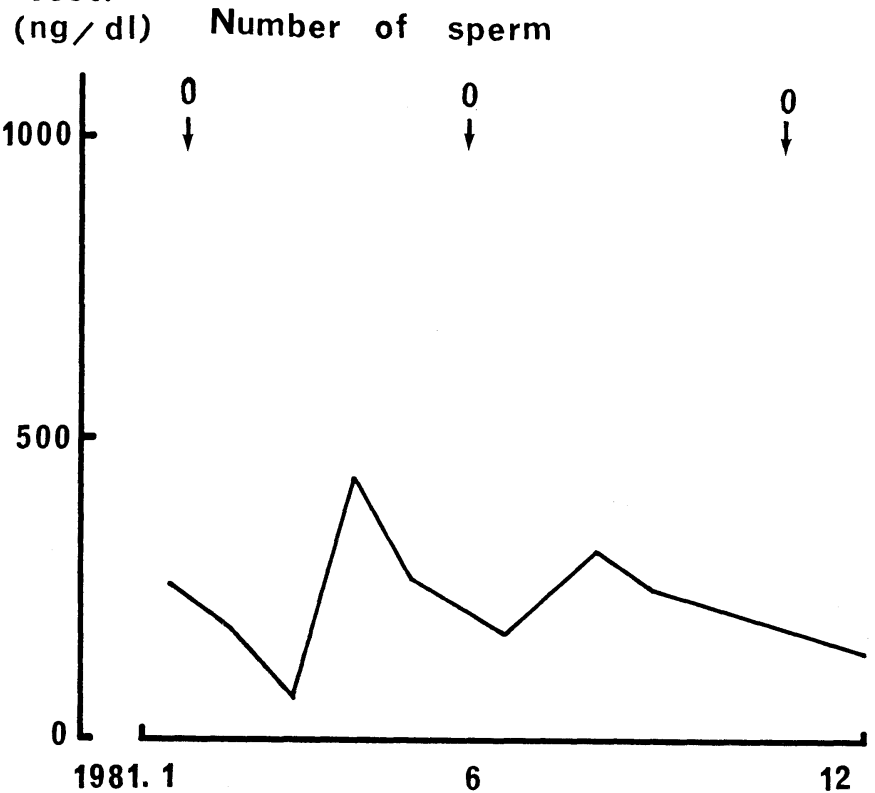

Fig. 2. Clinical course before gonadotropin treatment. 


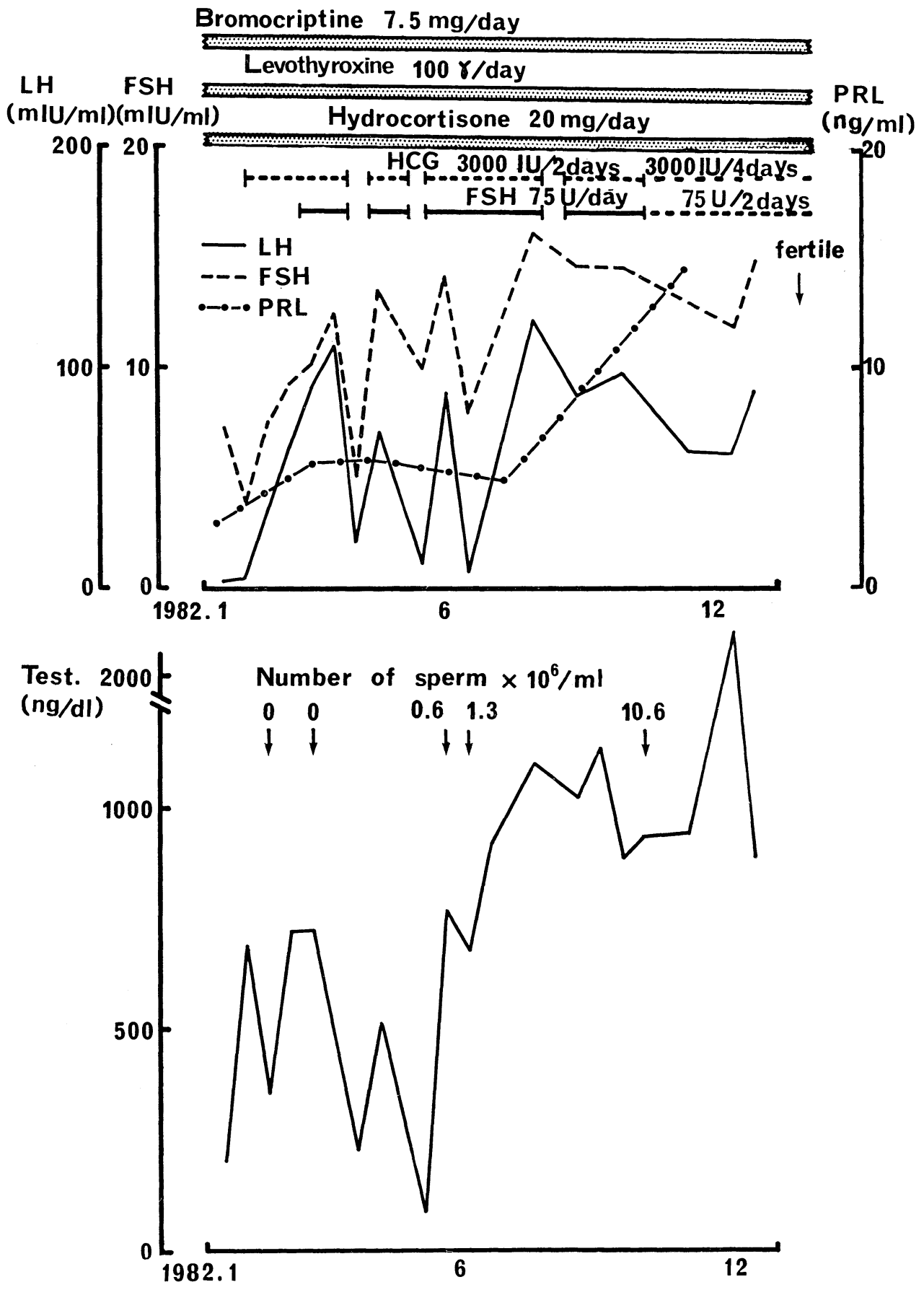

Fig. 3. Clinical course during gonadotropin treatment. 


\section{Results}

The clinical course before gonadotropin treatment is shown in Fig. 2. Plasma prolactin remained low throughout this course. Plasma LH was completely suppressed, but FSH levels were in a low normal range. Plasma testosterone levels were in the low normal or subnormal range. The sperm count revealed complete azoospermia all the time. The course of gonadotropin therapy is shown in Fig. 3. Plasma testosterone increased to near $500 \mathrm{ng} / \mathrm{dl}$ shortly after injections of $\mathrm{HCG}$ (HCG, Mochida pharma. Co.), 3,000 IU every second day. To stimulate spermatogenesis, 75 IU of FSH (Humegon, Sankyo Pharma. Co.) was added daily from the $3 \mathrm{rd}$ month. The combined HCG and FSH therapy kept the plasma testosterone levels the same as before with normal libido, potence and a sensation of well-being. At the 6 month of therapy, $0.6 \times 10^{6} / \mathrm{ml}$ of sperm was counted for the first time. As plasma testosterone levels tended to be higher in the latter 6 months of treatment, doses of HCG and FSH were reduced to half. Plasma $\mathrm{LH}$ and FSH were found to be 50-100, and 10-20 $\mathrm{mIU} / \mathrm{ml}$ throughout the course of treatment except for interruptions for his own personal reasons.

Crossreactivities of HCG, Mochida and Humegon to LH assay were revealed to be 85.3 and $0.5 \%$ on a unit basis, while those of Humegon and HCG to FSH were $7.5 \%$ for the former and negligible for the latter. Sperm counts gradually increased and reached a fertile range of $10.6 \times 10^{6} / \mathrm{ml}$ in the 11 th month. His wife was impregnated in the 12th month and gave birth to a normal baby girl.

\section{Discussion}

Since the first report by Gemzell and Kjessler (1964) of the successful treatment of infertility in a man with FSH, there have been several reports of ganadotropin therapy for male hypogonadotropic eunuchoidism (Johnsen, 1978; Luboshitzky et al., 1979; Mancini et al., 1979; Santen et al., 1973; Shill et al., 1979 and Weinstein and Reitz, 1974). Among these a report concerning hypogonadism due to hyperprolactinemia was unusual (Luboshitzky, 1979). Although hyperprolactinemia is easily treatable, either medically or surgically, permanent hypogonadotropic hypogonadism associated with prolactinoma is a very serious problem.

The regimen of gonadotropin therapy has been varied. We performed a combined therapy of HCG and HMG for the restoration of complete gonadal function and fertiltty. Plasma testosterone increased immediately to the normal range with several injections of HCG alone, but spermatogenesis was restored only after the addition of $75 \mathrm{IU}$ of FSH daily for 6 months. There were several reports indicating that HCG alone initiated (Bremner et al., 1981) or maintained spermatogenesis after it had been initiated by combined therapy of HCG and HMG (Johnsen, 1978). It was also reported that testosterone alone stimulated spermatogenesis in stalk-sectioned rhesus monkeys (Marshall et al., 1983). In general, relatively high doses of HCG were used in previous reports. Santen and Paulsen (1973) used $4,000 \mathrm{IU}$ of HCG three times a week in order to stimulate testosterone production. Weinstein and Reitz (1974) administered $5,000 \mathrm{IU}$ of HCG three times a week to a gonadotropin deficient male to achieve a normal concentration of plasma testosterone. Shill et al (1979) reported that 2,000 IU of HCG with $75 \mathrm{IU}$ of FSH three times a week resulted in successful spermatogenesis in $85 \%$ of the eunuchoid patients. It was 
also demonstrated in our present work that fairly large amounts of HCG and FSH were required to maintain plama testosteone levels in the normal range. This may be due to a refractoriness of the testes because of long-standing secondary hypogonadism. Plasma testosterone tended to be higher in a later period of treatment, even to half the amount of gonadotropins, suggesting a gradual recovery of the responsiveness of Leydig cells to gonadotropin. On the other hand, a desensitization of the testes during chronic treatment with gonadotropin was pointed out by D'Agata et al. (1982).

Successful treatment of a hypogonadal man with a combination of gonadotropin and bromocriptine following an operation for macroprolactinoma was reported.

\section{Acknowledgements}

Authors deeply wish to thank to Prof. N. Sasano, Dept. of Pathology, Tohoku Univ. for examining and describing the findings of testicular biopsy.

This work was partly supported by a research grant for "Specific Diseases" from the Japanese Ministry of Health and Welfare, and by a research grant from the Japanese Ministry of Education.

\section{References}

Bremner, W. J., A. M. Matsumoto, A. M. Sussman and C. A. Paulsen (1981). Follicle-stimulating hormone and human spermatogenesis. J. Clin. Inv. 68, 1044-1052.

D'Agata, D., E. Vicari, A. Aliffi, G. Maugeri, A. Mongiol and S. Gulizia (1982). Testicular responsiveness to chronic human chorionic gonadotropin administration in hypogonadotropic hypogonadism. J. Clin. Endocr. 55, 7680.

Gemzell, C. and B. Kjessler (1964). Treatment of infertility after partial hypophysectomy with human pituitary gonadotrophins. Lancet 1, 644 .

Johnsen, S. G. (1978). Maintenance of spermatogenesis induced by HMG treatment by means of continuous treatment in hypogonadotropic men. Acta Endocr. 89, 763-769.

Luboshitzky, R., E. Rosen, S. Trestian, and I. M. Spitze. (1979). Hyperprolactinemia and hypogonadism in men. Clin. Endocr. 11, 217-223.

Mancini, R. E., A. C. Seigver, and A. Perez Lioret (1969). Effect of gonadotropins on the recovery of spermatogenesis in hypophysectomized patients. J. Clin. Endocr. 29, 467-478.

Marshall, G. R, E. J. Wickings, D. K. Ludecke and E. Nieschlag (1983). Stimulation of spermatogenesis in stalk-sectioned-rhesus monkeys by testosterone alone. J. Clin. Endocr. 57, 152159.

Santen, R. J. and C. A. Paulsen. (1973). Hypogonadotropic eunuchoidism. II. Gonadal responsiveness to exogenous gonadotropins. $J$. Clin. Endocr. 36, 55-63.

Shill, W. B. (1979). Recent progress in pharmacological-therapy of male subfertility. A review. Andrologia 11, 77-107.

Weinstein, R. L. and R. E. Reitz (1974). Pituitarytesticular responsiveness in male hypogonadotropic hypogonadism. J. Clin. Inv. 53, 408-415. 